\title{
"Livre della vie des sainz apostres". Légendier d'apôtres en scripta franco-italienne (Ms. Lyon, Bibliothèque Municipale, 866), présenté et édité par Jean-Pierre Perrot
}

\section{Barbara Ferrari}

\section{OpenEdition}

\section{Journals}

Edizione digitale

URL: http://journals.openedition.org/studifrancesi/7831

DOI: $10.4000 /$ studifrancesi.7831

ISSN: 2421-5856

Editore

Rosenberg \& Sellier

\section{Edizione cartacea}

Data di pubblicazione: 1 juillet 2009

Paginazione: $370-371$

ISSN: 0039-2944

\section{Notizia bibliografica digitale}

Barbara Ferrari, «"Livre della vie des sainz apostres". Légendier d'apôtres en scripta franco-italienne (Ms. Lyon, Bibliothèque Municipale, 866), présenté et édité par Jean-Pierre Perrot», Studi Francesi [Online], 158 (LIII | II) | 2009, online dal 30 novembre 2015, consultato il 09 janvier 2021. URL: http:// journals.openedition.org/studifrancesi/7831 ; DOI: https://doi.org/10.4000/studifrancesi.7831

Questo documento è stato generato automaticamente il 9 janvier 2021.

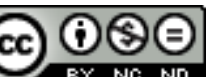

Studi Francesi è distribuita con Licenza Creative Commons Attribuzione - Non commerciale - Non opere derivate 4.0 Internazionale. 


\title{
"Livre della vie des sainz apostres". Légendier d'apôtres en scripta franco- italienne (Ms. Lyon, Bibliothèque Municipale, 866), présenté et édité par Jean-Pierre Perrot
}

\author{
Barbara Ferrari
}

\section{NOTIZIA}

"Livre della vie des sainz apostres". Légendier d'apôtres en scripta franco-italienne (Ms. Lyon, Bibliothèque Municipale, 866), présenté et édité par Jean-Pierre PERROT, Chambéry, Université de Savoie, 2006 («Laboratoire Langages, Littératures, Sociétés. Collection Corpus, 3»), pp. 372.

J.-P. Perrot, autore di un importante studio d'insieme sulle raccolte agiografiche francesi medievali (Le Passionnaire français au Moyen Âge, Genève, 1992), fornisce qui l'edizione di un leggendario conservato alla Bibliothèque Municipale di Lione (ms. 866, anc. 770) che riunisce tredici leggende apostoliche e le passioni dei santi Longino, Dionigi, Cosma e Damiano, Sette Dormienti. Come si legge nella sottoscrizione in versi che chiude la raccolta, il codice è stato esemplato da un copista prigioniero (f. 96d: $L i$ prizon qui moy excrist/ puisse aler avec Jhesu Crist...). La scripta franco italiana e lo stile delle miniature che inaugurano ciascuna leggenda situano l'esecuzione in Italia settentrionale; l'area di produzione non va però identificata con la regione veneziana, come sostiene Perrot (p. 20) - riprendendo in parte l'opinione di Paul Meyer - sulla scorta di alcune scritte sui fogli di guardia e di una nota di possesso del secolo xv. Una nota più antica, probabilmente coeva alla copia, e le caratteristiche iconografiche assegnano infatti il codice all'area ligure-genovese (cf. F. Avril, M.Th. Gousset, Cl. Rabel, 
Manuscrits enluminés d'origine italienne, Paris, B.N. (XIII ${ }^{e}$ s.), Paris 1984; F. Cigni, Copisti prigionieri, in Studi di Filologia Romanza offerti a V. Bertolucci Pizzorusso, Pisa 2006, pp. 437-39).

Nell'Introduzione Perrot affronta in primo luogo il problema della formazione della raccolta (La formation du légendier, pp. 9-21). Il manoscritto di Lione appartiene al ramo franco italiano del cosiddetto 'Passionnaire français', un fondo comune di leggende in prosa (traduzioni o adattamenti di vitae e passiones latine) che si è costituito gradualmente a partire dalla metà del secolo xIII. A questa famiglia, già individuata $\mathrm{e}$ studiata da Paul Meyer, che l'aveva identificata come 'Leggendario A', appartengono altri tre codici che, oltre al nucleo di leggende apostoliche, contengono vari testi agiografici, tra cui due traduzioni, in francese e in pisano, di alcuni capitoli della Legenda aurea; si tratta dei mss. Parigi, BnF, naf 23686; Tours, Bibl. Munic., 1008; Modena, Bibl. Estense Univ. Alfa T.4.14. I due ultimi, anch'essi di mano italiana, risultano strettamente apparentati al ms. di Lione, probabilmente copie indipendenti di un ascendente comune (su questo gruppo di codici e sul loro contesto di produzione cfr. F. Cigni, Genova e una versione toscana della "Legenda aurea", in Poeti e poesia a Genova (e dintorni) nell'età medievale, Genova 2006, pp. 43-67). Come ricorda Perrot, le passioni che compongono la raccolta lionese sono il frutto di tradizioni leggendarie e manoscritte molto diverse che lo studioso ricostruisce con grande ricchezza di dati (Les Passions et leurs sources, pp. 21-58). Segue un utile riassunto di ciascun testo (Analyse des Passions, pp. 59-80).

3 La nota linguistica (Langue du manuscrit, pp. 81-96) si avvale di strumenti un po' generici e ridotti di fronte alla complessità dell'esemplare. Essa non si propone come un esame sistematico della scripta franco-italiana in cui è redatto il leggendario, scripta composita "dont il semblerait qu'elle soit par bien des aspects propre à nostre copiste" (p. 81), ma si limita a segnalare tratti specifici e tendenze maggioritarie; si tratta peraltro di un'ampia disamina che approfondisce soprattutto gli aspetti graficofonetici. Nel capitolo dedicato ai Principes d'édition (pp. 96-99), Perrot sottolinea la mediocre qualità della copia; egli sceglie tuttavia di intervenire sul testo solo con le correzioni indispensabili, ricorrendo in questi casi principalmente alla lezione dei manoscritti di Tours e Modena. Pur segnalando tra le abitudini grafiche del copista la pratica costante dell'agglutinazione, l'editore, per una giusta preoccupazione di leggibilità, sceglie di separare le parole secondo l'uso odierno, mantenendo il raddoppio della consonante iniziale (cf. p. 115: de lla, en lliquele, a llui); questo principio è applicato con rigore nel testo critico, ma sia sulla copertina, sia nel frontespizio compare invece la forma agglutinata della vie. L'edizione del leggendario (pp. 113-351), preceduta dalla riproduzione delle diciotto lettere istoriate (pp. 101-111) è condotta con accuratezza. Tutti gli interventi sono puntualmente segnalati in apparato, ma in alcuni punti l'oscurità del testo avrebbe forse richiesto la presenza di note esplicative. L'indice dei nomi (pp. 352-359) e un glossario selettivo (pp. 360-372) completano l'insieme. A JeanPierre Perrot va senz'altro riconosciuto il merito di aver reso disponibile un documento linguistico di sicuro interesse e di aver arricchito l'ancora assai esiguo drappello delle edizioni di raccolte agiografiche francesi medievali. 